\title{
The Impact of COVID-19 on the Movement of Trucks Between Canada and the US: Evidence from the Ambassador Bridge
}

\author{
Hanna Maoh ${ }^{1}$ (i) ${ }^{\text {a }}$, William Anderson ${ }^{1}$ \\ ${ }^{1}$ Cross-Border Institute, University of Windsor, Ontario, Canada \\ Keywords: covid-19, trucks, traffic, cross-border, ambassador bridge \\ https://doi.org/10.32866/001c.24958
}

\section{Findings}

\begin{abstract}
The ongoing COVID-19 pandemic has closed land borders for non-essential travel between Canada and the US since the middle of March 2020. This paper explores if the pandemic has had a significant impact on the patterns of truck movements between the two countries. The volume of trucks that crossed the Ambassador Bridge (busiest land border in Canada) between August 1, 2019 and February 28,2021 is analyzed. We found that truck volume dropped only during the first two months of the pandemic. Truck traffic increased significantly in May to reach higher than normal levels and then normalized after November 2020.
\end{abstract}

\section{QUESTIONS}

This paper explores the volume of trucks that crossed the Ambassador Bridge, the busiest land border crossing in Canada, during the period August 1, 2019 and February 28, 2021. We utilize an extensive dataset obtained from a traffic sensor operated by the City of Windsor to evaluate the trends before and after the pandemic. The exploration is focused on answering the following questions:

- Did the COVID-19 pandemic impact the volume of trucks between Canada and the US across the Ambassador Bridge?

- What type of traffic trends have emerged after the pandemic and were these consistent over time?

\section{METHODS}

The focus of this research is the Ambassador Bridge connecting Windsor, Ontario to Detroit, Michigan (Figure 1). On average, the bridge facilitates the movement of over 5,000 trucks per day per direction. The bridge handles around $42 \%$ of all the trucks moving between Ontario and the US, and vice versa (Maoh et al. 2021). The Ambassador Bridge handles a large number of trucks that are associated with the manufacturing and transportation industries. More specifically, $19 \%$ and $20 \%$ of all Canada- and US-bound truck trips crossing the bridge were associated with the manufacturing industry. Similarly, 34\% and 19\% of all Canada- and US-bound truck trips were associated with the transportation industry (Gingerich, Maoh, and Anderson 2016). According to Maoh et al. (2021), the top two Canada-US commodity 


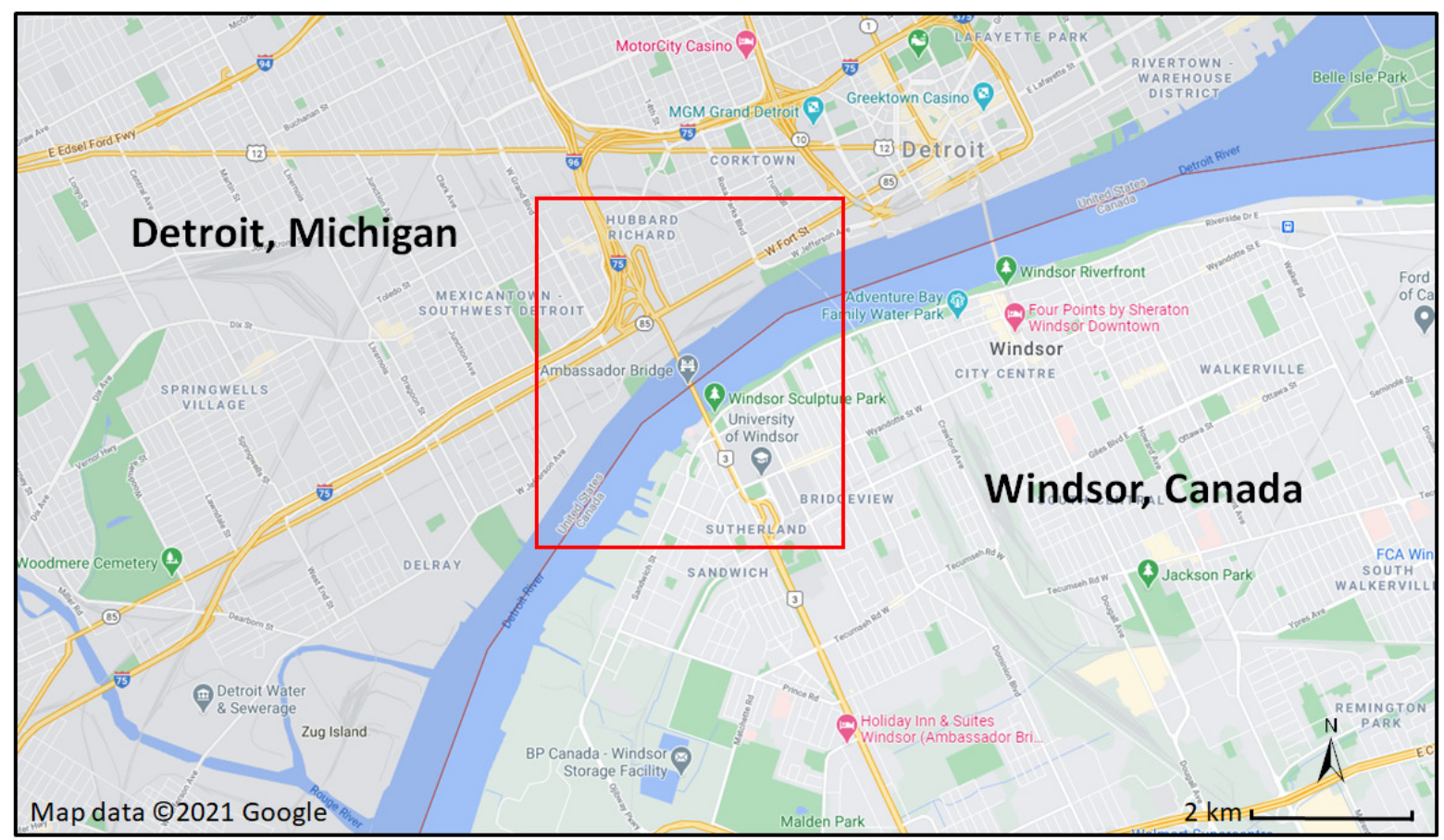

Figure 1. Study area

flows in terms of US dollars in 2019 were machinery/electrical and transportation. More specifically, the total value of these two commodity groups was $\$ 29.69$ and $\$ 28.26$ billion US dollars in 2019 , respectively. These figures highlight the importance of the Ambassador Bridge to the Canadian manufacturing industry, namely the automotive sector.

The primary dataset is based on recorded observations that are collected via a traffic camera that is located at the intersection of Huron Church Road and Dorchester Road. The intersection is about $1.3 \mathrm{~km}$ away from the approach leading to the Ambassador Bridge and as such is able to detect trucks moving in both directions between the two countries. The traffic camera was installed at the intersection on July 15, 2019 and has been collecting data since then. The data is accessible through an OpenData API that is managed by the City of Windsor. ${ }^{1}$ The camera collects data on a minute-by-minute basis by the type of vehicle (i.e., Articulated truck, Single unit truck, Light vehicle, Motorized vehicle, Work van, Bus, and Bicycle) that went through the intersection in any given direction. The data used in the analysis considered articulated and single unit trucks as these are the two types of commercial vehicles that typically cross the Ambassador Bridge between the two countries. 


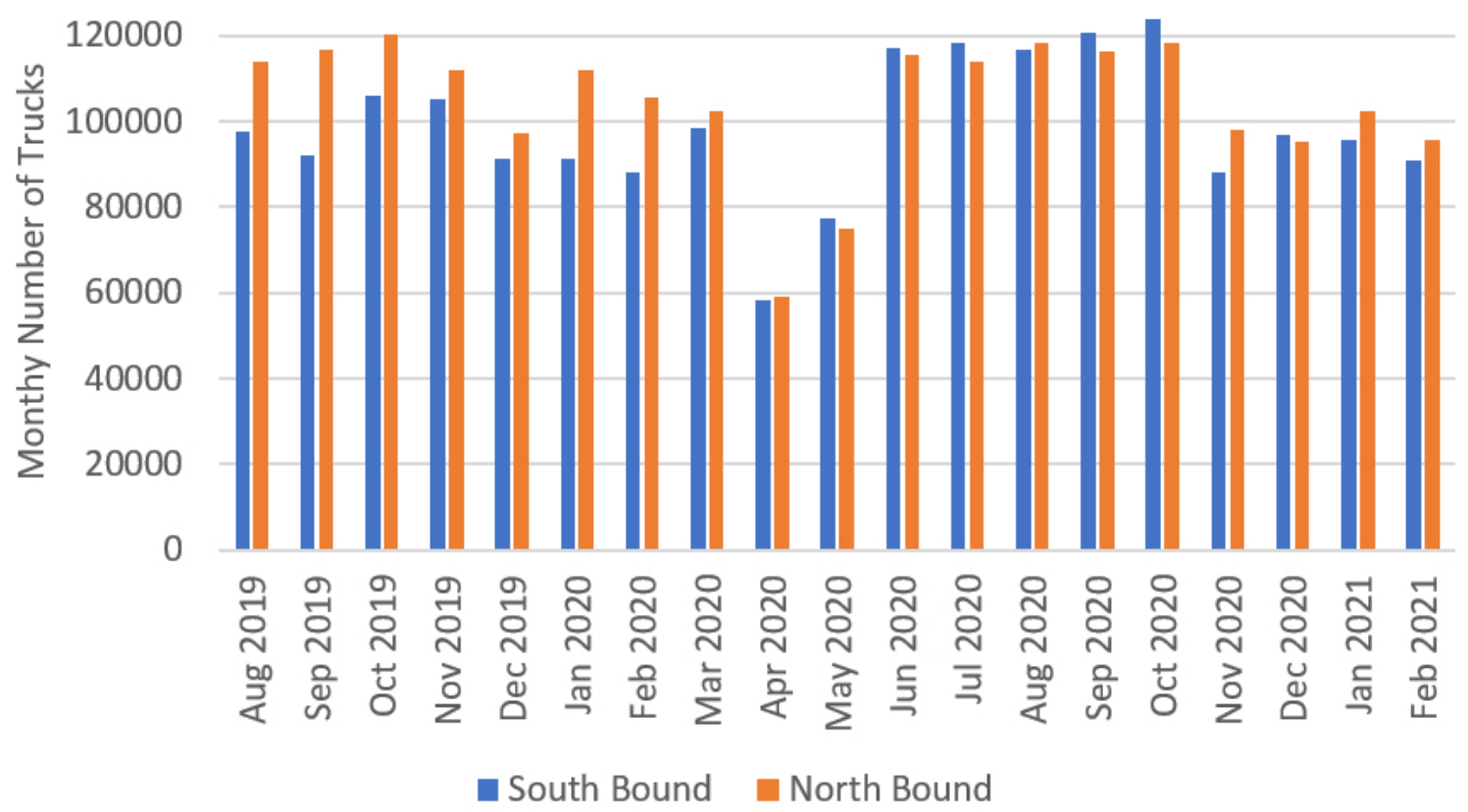

Figure 2. Observed monthly trucks heading from/to the Ambassador Bridge, Aug 2019 - Feb 2021

\section{FINDINGS}

The observed articulated and single unit trucks were aggregated by month and traffic direction, as shown in Figure 2. The monthly average number of USbound trucks moving on Huron Church Rd towards the Ambassador bridge before the pandemic (i.e., Aug 2019 - Feb 2020) was just over 111,000. On the other hand, the monthly average number of Canada-bound trucks before the pandemic was around 96,000. The number of trucks crossing in both directions did not deviate from the monthly averages during March 2020. However, the highest impact is observed for the month of April 2020. The onset of the pandemic led to a $39 \%$ and $46 \%$ drop in the number of Canadaand US-bound trucks, respectively, during April 2020. The numbers started climbing back in May but remained below the post-pandemic monthly averages.

Interestingly, the average monthly numbers climbed to above the prepandemic averages during the summer and early fall of 2020. More specifically, the monthly average number of Canada- and US-bound trucks during the months of June to October 2020 were around 119,000 and 116,000, respectively. There is a clear increase in the Canada-bound monthly average truck traffic during these months which translate into a $24 \%$ growth compared to the pre-pandemic months. The observed growth tends to taper off starting in Nov 2020. The average monthly numbers during the months of Nov 2020 to Feb 2021 appear to be comparable to the monthly averages observed before 
the beginning of the pandemic. More specifically, the monthly averages for the Canada- and US-bound truck traffic were around 93,000 and 98,000, respectively.

The declining patterns in Figure 2 after March 2020 indicate that the first lockdown in April 2020 was more likely associated with uncertainty that led manufacturing facilities in many industries, including the automovtive sector, to shutdown to adhere to the public policy set to prevent the spread of infection in the workplace. However, most manufacturing facilities were able to adapt quickly by instituting employee screening and introducing major changes to factory floor activities to avoid close contacts among employees. Consequently, production resumed and so did the movement of trucks between the two countries starting in June 2020.

The average hourly profile for truck movements in both directions for four different month groups are presented in Figure 3. The choice of these month groups is based on the trends observed in Figure 2. The purpose here is to highlight if the daily patterns of truck movements on the Ambassador Bridge have been affected by these trends, namely pre-pandemic (i.e., normal period prior to March 2020), onset of pandemic with major decline in truck movement (i.e., April and May 2020), recovery or catching up period (i.e., summer months and early fall of 2020), and back to pre-pandemic (i.e., back to normal averages period starting in November 2020). The highest peak for Canada-bound traffic is observed during the afternoon hours (i.e., 1:00 pm - 5:00 pm). By comparison, the highest peak for the US-bound traffic starts much earlier and tends to remain steady from 9:00 am to 4:00 pm. According to the plotted curves, the pandemic did not seem to impact the hourly pattern of traffic on the Ambassador bridge. The correlations between the prepandemic months (i.e., Aug 2019 - Mar 2020) and post-pandemic months are shown in Table 1 . As can be seen, the correlations are high and consistent over time. The lowest correlation (0.954) is for the two months that followed the beginning of the lockdown due to the pandemic in the case of US-bound traffic. However, the reported correlation is significantly high suggesting no change in the hourly profiles. This is indicative that the pandemic had an impact on the volume of trucks but not the daily logistical operation of supply chains. In a nuttshell, the performed analysis indicates that the industrial supply chains across the Canada-US border are highly resilient to unexpected events such as the COVID-19 pandemic. 
(a)

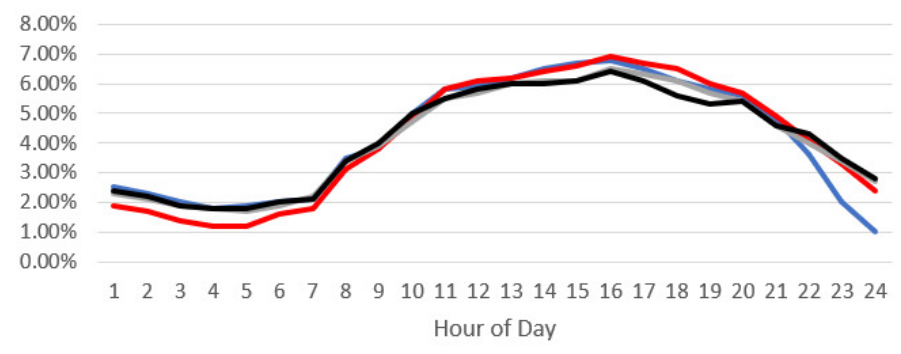

(b)

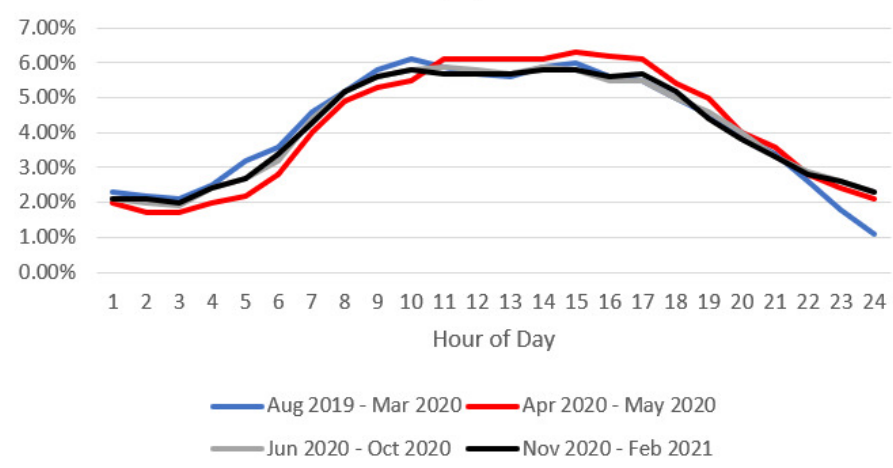

Figure 3. Hourly profiles of truck flow during different months for (a) Canada-bound and (b) US-bound traffic

Table 1. Correlation of truck flow hourly profiles on the Ambassador Bridge (pre-pandemic versus post-pandemic)

\begin{tabular}{|l|c|c|c|}
\hline \multirow{2}{*}{} & \multicolumn{3}{|c|}{ Aug 2019-Mar 2020 Versus } \\
\cline { 2 - 4 } & Apr 2020 - May 2020 & Jun 2020 - Oct 2020 & Nov 2020 - Feb 2021 \\
\hline Canada-bound & 0.968 & 0.969 & 0.964 \\
\hline US-bound & 0.954 & 0.977 & 0.979 \\
\hline
\end{tabular}

This is an open-access article distributed under the terms of the Creative Commons Attribution 4.0 


\section{REFERENCES}

Gingerich, Kevin, Hanna Maoh, and William Anderson. 2016. "Characterization of International Origin-Destination Truck Movements across Two Major U.S.-Canadian Border Crossings.” Transportation Research Record: Journal of the Transportation Research Board 2547: 1-10. https://doi.org/10.3141/2547-01.

Maoh, Hanna, Terence Dimatulac, Shakil Khan, and Marek Litwin. 2021. "Studying Border Crossing Choice Behavior of Trucks Moving between Ontario, Canada and the United States." Journal of Transport Geography 91: 102992. 